\title{
DIGITAL WEIGHING MACHINE
}

\author{
Roopmani Singh \\ Department of ECE \\ MIT School of Engineering, Pune, \\ Maharashtra, India \\ Sakshat Bankar \\ Department of ECE \\ MIT School of Engineering, Pune, \\ Maharashtra, India
}

\begin{abstract}
The demand for precise weight measurement and storage is increasing day by day in today's developing world. The weighing machine is an extremely useful equipment. It assists us in determining our weight as well as the weight of other things. Weighing machines are utilized in a variety of industries and businesses. It is impossible to ascertain the exact weight of anything without the use of a weight machine. This technology could be employed in a variety of industries, including agriculture, as well as in laboratories where more exact and reliable results are required. One of the most significant operations in enterprises is the precise measurement and storing of weight. Mechanical weighing machines have been phased out in favour of electronic weighing machines, which offer benefits such as accuracy, dependability, and a wide range of applications.
\end{abstract}

Keywords - LOAD CELL, MICROCONTROLLER, ULTRASONIC SENSOR, WEIGHING MACHINE, WIFI.

\section{INTRODUCTION}

Because measuring weight with a digital weighing machine is user friendly and has a variety of applications, the demand for digital weighing machines is expanding day by day in most business operations. It is not a new notion to calculate BMI using a formula; in the 19th century, a Belgian statistician called Adolph Quetelet created the Quetelet Index of Obesity. BMI is determined by dividing a person's weight in kilograms by the square of their height in inches, according to his index. Prior to 1980, physicians used charts to estimate weight and height, which were different for men and women and included a range of body weights. However, these charts were flawed because they were based solely on weight and not on body composition [1]. Currently, there has been significant progress in BMI calculation, such as the automatic calculation of height and weight using a formula, and the data is then automatically input into a computer, which displays the person's BMI on a

\author{
Subham Das \\ Department of ECE \\ MIT School of Engineering, Pune, \\ Maharashtra, India \\ Prof. Monika Bhoyar \\ Department of ECE \\ MIT School of Engineering, Pune, \\ Maharashtra, India
}

monitor screen or LCD display. The AT89S52 microcontroller controls the many components of the Digital Weighing Machine. The load cell converts the force applied to it into a measured electrical output, and the weight output processed by the microcontroller is displayed on the LCD display. The ultrasonic sensor will be used to calculate a person's height, which will aid in the computation of BMI, and the Wi-Fi module will connect the microcontroller to a Wi-Fi network. The Microcontroller unit will be in charge of the entire system. The body Mass Index may be used to estimate the overall fat content of a person's body. The BMI is calculated using two variables: the person's height and weight. Despite the fact that the BMI does not provide a precise assessment of total body fatness, numerous studies have found that it is linked with total body fat, similar to other methods of body fat computation such as dual energy $\mathrm{x}$-ray absorptiometry and underwater weighing techniques [1], [2]. In comparison to other body fat detection techniques, BMI is a commonly utilized approach owing to its low cost and ease of calculation of health risks associated with obesity.

\section{METHODOLOGY}

The goal of the project was to create a microcontroller-based automated Body Mass Index (BMI) calculator with an LCD display and Wi-Fi module that calculates the BMI based on two simple parameters: weight and height. The project's hardware comprises of a load cell or a weighing scale. Technique that is used to compute a person's body weight has a height calculating system built in, which is used to calculating a person's height the individual's weight computed in kilograms and height in meters based on The BMI formula is a formula for calculating a person's height and weight.[1] When it comes to controlling your weight and keeping a healthy lifestyle, the microcontroller-based automatic Body Mass Index calculator is a handy tool. The load cell calculates the person's weight and turns the mechanical force into electrical signals that can be easily obtained after microcontroller processing. When an ultrasound sensor with 
built-in transmits and receive electronics transits an ultrasonic signal, it reflects back to the receiver after impacting an object or person, and height is determined by multiplying the speed of the ultrasound signal by the time it takes to return to the sensor. All of this information is processed by a microprocessor, and the outcome is sent to display with the help of Wi-Fi module. BMI is merely a rough estimate for evaluating potential weight concerns; it is not a diagnostic tool. If a person's BMI is too high, they are putting themselves at risk. Using these metrics, a physician can advise on various health risks associated with weight. For example, skin fold measures, a person's fitness, a nutritionist's decision on a person's diet, and other health screenings.

A. Calculation of BMI: The calculation of BMI can be calculated with the help of given standard formula.

BMI $=[$ (Weight in Kilograms / (Height in Meters $\mathrm{x}$ Height in Meters)] [1].

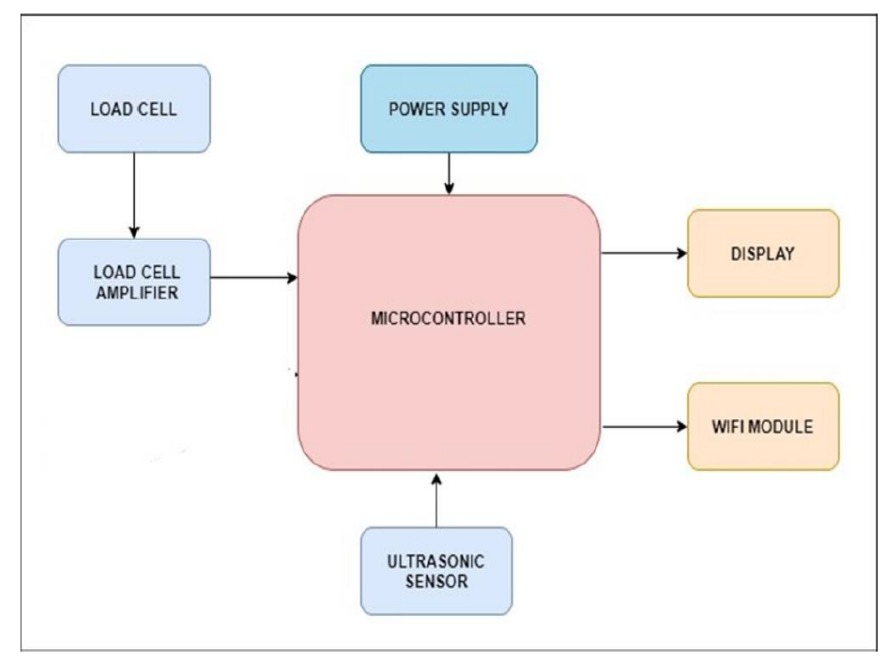

Fig .1 Block Diagram

\section{SYSTEM REQUIREMENT}

The following are the basic analogue components that must be employed in the circuit design:

1. AT89S52 Microcontroller: The AT89S52 is part of Atmel's renowned 8051 microcontroller family. It's an 8-bit CMOS microcontroller with 256 bytes of RAM and $8 \mathrm{~K}$ of Flash memory. These microcontrollers are industry standard since they are based on the 8051 architectures. Three 16-bit timers, external interrupts, a full-duplex serial port, an onchip oscillator, and clock circuits are among the 32 I/O pins. The AT89S52 is a CMOS 8-bit Microcontroller with $8 \mathrm{k}$ bytes of in-system programmable flash memory and 256 bytes of RAM that is low-power and high-performance.
[3]

\begin{tabular}{|c|c|c|c|}
\hline \multirow[b]{2}{*}{ (T2) P1.0 } & \multicolumn{2}{|c|}{$\circlearrowright$} & \\
\hline & 1 & 40 & $\boxminus$ vcc \\
\hline (T2 EX) P1.1 & 2 & 39 & $\square$ PO.0 (ADO) \\
\hline $\mathrm{P} 1.2$ & 3 & 38 & $\square \mathrm{P} 0.1$ (AD1) \\
\hline $\mathrm{P} 1.3 \square$ & 4 & 37 & $\square$ P0.2 (AD2) \\
\hline $\mathrm{P} 1.4 \square$ & 5 & 36 & $\square$ P0.3 (AD3) \\
\hline (MOSI) P1.5 & 6 & 35 & $\square$ P0.4 (AD4) \\
\hline (MISO) P1.6 & 7 & 34 & $\square$ P0.5 (AD5) \\
\hline (SCK) P1.7 & 8 & 33 & $\square$ P0.6 (AD6) \\
\hline RST $\square$ & 9 & 32 & $\square$ P0.7 (AD7) \\
\hline$(R \times D)$ P3.0 & 10 & 31 & $\square \overline{\mathrm{EA}} / \mathrm{VPP}$ \\
\hline (TXD) P3.1 & 11 & 30 & $\square$ ALE/PROG \\
\hline (INT0) P3.2 & 12 & 29 & $\square \overline{\text { PSEN }}$ \\
\hline (INT1) P3.3 $\square$ & 13 & 28 & $\square$ P2.7 (A15) \\
\hline (T0) P3.4 & 14 & 27 & P P2.6 (A14) \\
\hline (T1) P3.5 ᄃ & 15 & 26 & $\square$ P2.5 (A13) \\
\hline 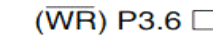 & 16 & 25 & $\square$ P2.4 (A12) \\
\hline ( $\overline{\mathrm{RD}}) \mathrm{P} 3.7$ & 17 & 24 & $\square$ P2.3 (A11) \\
\hline XTAL2 ᄃ & 18 & 23 & $\square$ P2.2 (A10) \\
\hline XTAL1 & 19 & 22 & $\sqsupseteq$ P2.1 (A9) \\
\hline GND $\square$ & 20 & 21 & $\square$ P2.0 (A8) \\
\hline
\end{tabular}

Fig .2 AT89S52 microcontroller

2. Ultrasonic Sensor: An ultrasonic sensor is a device that uses ultrasonic sound waves to detect the presence of an object and measure its distance. A transducer is used in an ultrasonic sensor to emit and receive ultrasonic pulses that relay information about the proximity of an item. Electrical signals are converted into ultrasonic signals by the transmitter, and ultrasound is converted into electrical signals by the receiver. The $\mathrm{HC}$ - SR04 ultrasonic ranging module has a non-contact measurement range of $2 \mathrm{~cm}$ to $400 \mathrm{~cm}$ with a ranging precision of $3 \mathrm{~mm}$. Ultrasonic transmitters, receivers, and a control circuit are included in the modules. The Vcc and Ground pins of the Sensor are used to supply a controlled $+5 \mathrm{~V}$ to the sensor. Because the sensor consumes less than $15 \mathrm{~mA}$, it can be powered directly from the on-board $5 \mathrm{~V}$ ports. Because the trigger and echo pins are also I/O pins, they can be connected to the microcontroller's I/O pins. 


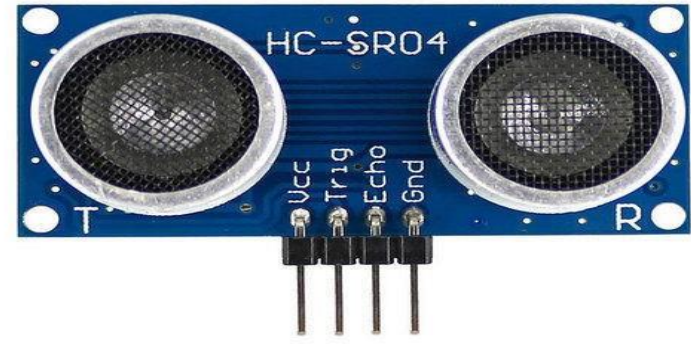

Fig-3: Ultrasonic sensor

3. Load cell: A load cell is a transducer that converts force into an electrical output that can be measured. A load cell converts mechanical force into digital values that can be read and recorded by the user. Hydraulic load cells, pneumatic load cells, capacitive load cells, strain gauge load cells, and more types of load cells exist. The strain gauge load cell is the most popular and widely utilised of all these types. The electrical voltage signal produced by a strain gauge load cell is proportional to the force exerted. However, the size of this output signal is relatively modest. A strain gauge's sensitivity is measured in millivolts per volt, which means that the maximum output is proportional to the excitation voltage.

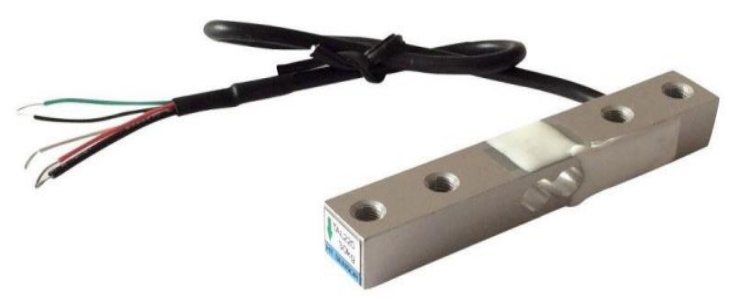

Fig-4: Load cell

4. Wi-Fi Module (ESP8266): The ESP8266 is a very user-friendly and low-cost device that allows us to link our creations to the internet. Because the module can function as both a hotspot and a station (connecting to $\mathrm{Wi}-\mathrm{Fi}$ ), it can simply retrieve data and post it to the internet, making the Internet of Things as simple as feasible. It can also retrieve data from the internet using APIs, allowing our project to access any information on the internet and so become wiser.

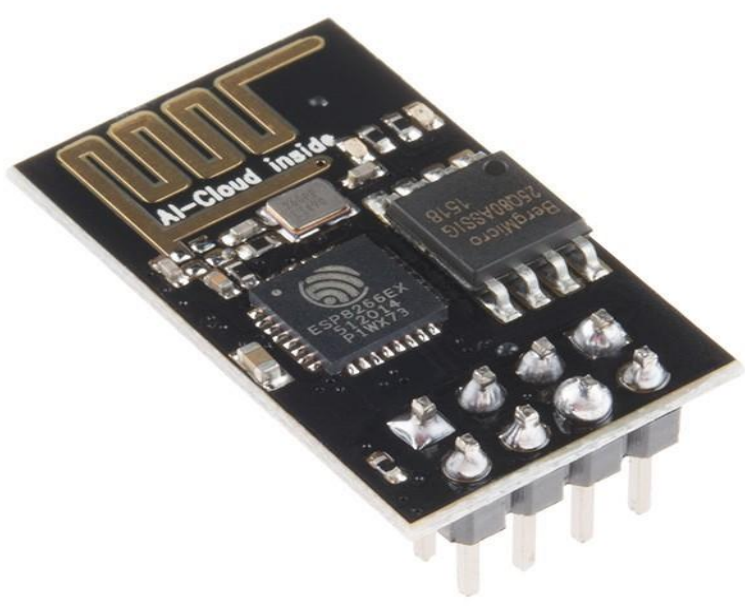

Fig-5: Wi-Fi Module

\section{SYSTEM DESIGN}

A load cell or a digital weighing machine is used to determine the person's weight. The ultrasonic sensor determines the individual's height. Ultrasounds are transmitted and received by an ultrasound sensor. It starts by emitting ultrasounds, which are reflected back after striking any object or person in its vicinity, which is then sensed by the sensor. The height is estimated by multiplying the 'ultrasound speed' by the 'time it takes for the ultrasounds to return to the sensor. The data from the Ultrasound Sensor and Load Cell is then passed to the microcontroller, which performs the calculations, and the result is then sent to the display device through Wi-Fi Module. Our weighing machine is a sleek, modern, and most significantly, precise electro medical gadget that measures one's height and weight in under a minute. Its key features include height and weight measurement, as well as a variety of other functions. Calculates BMI and displays the findings on an LCD screen; it's simple to use with minimal user interaction and produces reliable results. 


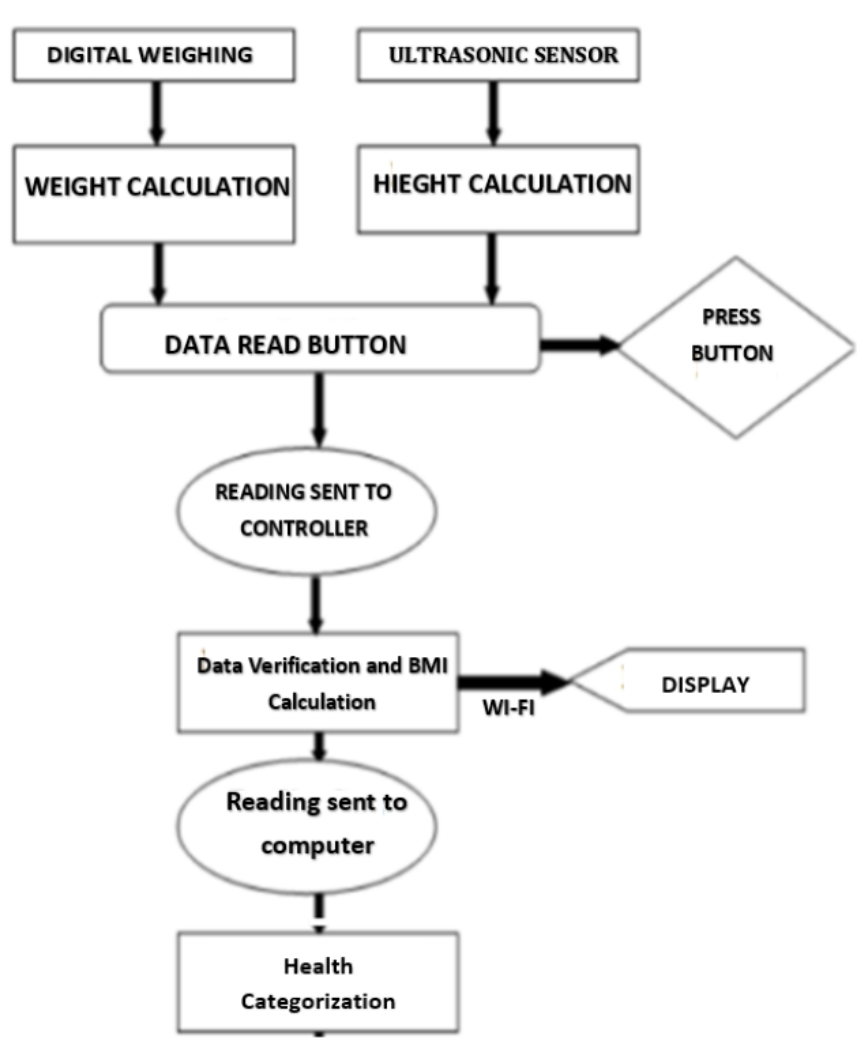

Fig.6: Flow Chart

\section{IMPLEMENTATION}

Figures 6 and 7 depict the design of our project as a block diagram and a circuit board for a weighting machine, respectively.

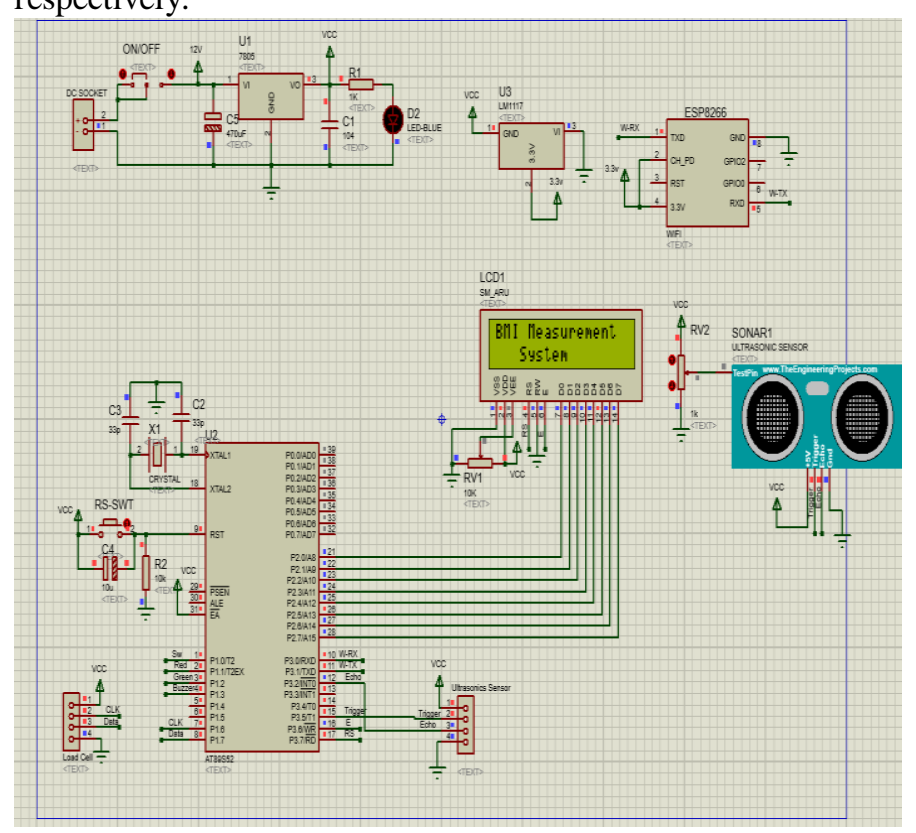

Fig 7: System implementation on Proteus
A load cell or a digital weighing machine is used to determine the person's weight. The ultrasound sensor determines the person's height; there is an ultrasonic sensor that both transmits and receives ultrasounds. It generates ultrasounds, which are reflected back after striking any object or person in its immediate vicinity. The height is estimated by multiplying the ultrasound's speed with the time it takes for the ultrasounds to return to the sensor. The data from the Ultrasound Sensor and the Load Cell is then passed to the microcontroller, which performs the computations and sends the result to the display device through WIFI. In the extensive field of Bio-Medical engineering, the Automatic Body Mass Index Calculator has various uses. The Automatic BMI Calculator is a device that is used in hospitals, clinics, and even pharmacies, since it is well-known that Bio-medical engineering is about the use of electronics to the field of medicine. We can use BMI for business applications by adding a coin acceptor device.

\section{RESULT}

The BMI is the term given to the ratio of a person's height and weight that represents the percentage of body fat to the weight of organs, muscles, or bone. A higher BMI indicates a larger fat content in the body. The major goal of our research was to create a machine that could automatically calculate a person's height and weight, as well as calculate their BMI. Our Automatic BMI Calculator is a modern, beautiful, computerized, and most importantly "accurate" medical equipment that measures one's height and weight in under a minute.[6]

\section{CONCLUSION}

The importance of BMI as a statistical instrument for calculating the Health Risk of various diseases may be concluded from our project study. The importance of BMI as a health indicator is revealed by the theoretical study we conducted at the start of our project. We discovered the application of the electronic principles we acquired in our course work by creating the various components of our Automatic Body Mass Index Calculator. We also learnt a lot about how to use mechanical principles, which are extremely important in any form of engineering application. We quickly improved our Micro-controller skills and discovered the huge range of Micro-Controller applications. We discovered the value of keeping information in black and white while putting together this report. It aided us throughout the project's various stages of implementation by serving as a steady guide in challenging situations. Last but not least, we learned the value of teamwork and how much easier journeys become when individuals collaborate with one another and help one another in difficult situations. 


\section{REFERENCES}

[1]. BMI Formula: An Overview, Using the Metric System. Written by/reviewed by: Arthur Schoenstadt, MD.

[2] Muhammad Ali Mazadi, Janice Gillispie Mazadi and Rolin D. McKinlay: "The 8051 Microcontroller and Embedded System Using Assembly And C" Pearson Education. (2009).

[3] H.V. Makthal, "Electronic Pressure Transducer Selection and Application" Journal of Instrumentation society India 28(I).

[4] Mei Z, Grummer-Strawn LM, Pietrobelli A, Goulding A, Goran MI, Dietz WH. Validity of body mass index compared with other body composition screening indexes for the assessment of body fatness. American Journal of Clinical Nutrition 2002; 7:597-985.

[5] Garrow JS and Webster J. Quetelet's index (W/H2) as a measure of fatness. International Journal of Obesity 1985; 9:147-153.

[6] Clinical Guidelines on the Identification, Evaluation, and Treatment of Overweight and Obesity in Adults.

[7] Michael Snyder, M.D. (2010). A Life without Dieting. Hay House, Inc.

[8] Design of an Embedded Platform for Digital Weighing System to Enhance Measuring Capabilities Dr. Pradeep B. Dahikar Mr. Kamlesh S. Patle Head - Dept. of Electronics, Kamala Nehru College, Nagpur, India1Project fellow, Dept. of Electronics, Kamala Nehru College, Nagpur, India.

[9] MICROCONTROLLER BASED WEIGHING MACHINE A.A. Mulla1, Z. A. Mulla2 1Yashwantrao Chavan College of Science, Karad -415 124, India 2Sadguru Gadage Maharaj College, Karad-415 124, India. 